\title{
Reproducibility of Random Amplified Polymorphic DNA (RAPD) Analysis among Laboratories
}

\author{
Greg A. Penner, ${ }^{1,3}$ Arla Bush, ${ }^{2}$ Roger Wise, ${ }^{2}$ Won Kim, ${ }^{3}$ Les Domier, ${ }^{4}$ Ken Kasha, ${ }^{5}$ \\ Andre Laroche, ${ }^{6}$ Graham Scoles, $^{7}$ Stephen J. Molnar, ${ }^{1}$ and George Fedak ${ }^{1}$
}

${ }^{1}$ Plant Research Centre, Central Experimental Farm, Agriculture Canada, Ottawa, Ontario, Canada K1A 0C6;

\begin{abstract}
${ }^{2}$ U.S. Department of Agriculture (USDA), Agricultural Research Service (ARS), Department of Plant Pathology, Iowa State University, Ames, Iowa, USA 50011; ${ }^{3}$ Agriculture Canada, Winnipeg Research Station, Winnipeg, Manitoba, Canada, R3T 2M9; ${ }^{4}$ USDA, ARS, University of Illinois, Urbana, Illinois, USA 61801; ${ }^{5}$ Department of Crop Science, University of Guelph, Guelph, Ontario, Canada, N1G 2W1; ${ }^{6}$ Agriculture Canada, Lethbridge Research Station, Main, Lethbridge, Alberta, Canada, T1J 4B1;

${ }^{7}$ Department of Crop Science and Plant Ecology, University of Saskatchewan, Saskatoon, Saskatchewan, Canada, S7N 0W0
\end{abstract}

Random amplified polymorphic DNA (RAPD) analysis appears to offer a cost- and time-effective alternative to restriction fragment-length polymorphism (RFLP) analysis. However, concerns about the ability to compare RAPD results from one laboratory to another have not been addressed effectively. DNA fragments that were amplified by five primers and shown to be reproducibly polymorphic between two oat cultivars (within the Ottawa laboratory) were tested in six other laboratories in North America. Four of the six participants amplified very few or no fragments using the ottawa protocol. These same participants were able to generate a considerable number of amplified fragments by using their own protocols. The reproducibility of results among laboratories was affected by two factors. First, different laboratories amplified different size ranges of DNA fragments, and, consequently, small and large polymorphic fragments were not always reproduced. Second, although reproducible results were obtained with four of the primers, reproducible results were not obtained with the fifth primer, using the same reaction conditions. It is suggested that if the overall temperature profiles (especially the annealing temperature) in- side the tubes are identical among the laboratories, then RAPD fragments are likely to be reproducible.

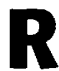

Wandom amplified polymorphic DNA (RAPD) analysis utilizes random 10-base oligonucleotides as primers to amplify discrete fragments of genomic DNA via PCR. ${ }^{(1,2)}$ This approach appears to offer an alternative to restriction fragmentlength polymorphism (RFLP) analysis for the identification of DNA polymorphisms that are linked to traits of commercial importance. RAPD analysis can be performed less expensively and more rapidly than RFLP analysis. These factors, coupled with the relative technical ease with which RAPD analysis can be conducted, has led plant breeders to consider using this technology in their selection programs. RAPD analysis has been used successfully to identify polymorphisms linked to disease-resistance genes in tomato, ${ }^{(3)}$ oats, ${ }^{(4)}$ and lettuce, ${ }^{(5,6)}$ and for genome mapping in $A r$ abidopsis thaliana. ${ }^{(7)}$

However, some concerns about the reproducibility of RAPD analysis both within a laboratory and among laboratories remain unresolved. ${ }^{(8,9)}$ Unless results generated by one laboratory can be reproduced both within that laboratory and by other laboratories, the potential advantages offered by RAPD analysis will not be realized. In the Ottawa laboratory, a number of RAPD primers have been identified that reproducibly amplify DNA fragment polymorphisms between two oat cultivars (G. Penner, unpubl.) We shared aliquots of five of these primers and samples of genomic DNA from the two cultivars, with six laboratories in the United States and Canada. Participants (see list below) were asked to test the primers and substrates using both the Ottawa protocol (henceforth referred to as the standard protocol) and the protocol currently in use in each participating laboratory. (These participants are referred to [by initials] throughout the text.)

1. Les Domier, USDA, ARS, University of Illinois (LD)

2. Won Kim, Agriculture Canada, Winnipeg (WK)

3. Arla Bush and Roger Wise, USDA, ARS, Iowa State University (AB)

4. Andre Laroche, Agriculture Canada, Lethbridge (AL)

5. Graham Scoles, University of Saskatchewan (GS)

6. Ken Kasha, University of Guelph (KK)

7. Greg Penner, Agriculture Canada, Ottawa (GP)

\section{MATERIALS AND METHODS}

RAPD primers were obtained from Dr. 


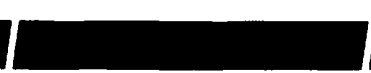

John Carlson (University of British Columbia, Vancouver, BC). Primers selected for inclusion in this study had all been shown previously to generate polymorphic fragments between the oat (Avena sativa L.) cultivars, Kanota and Ogle. These polymorphic fragments exhibited Mendelian segregation ratios $(1: 1)$ over at least 70 individual $F_{6}$ segregants derived by single-seed descent from a cross between the two parents (see Table 1 for a list of the primers used and their sequences). Genomic DNA was extracted from the oat cultivars by the method of McCouch et al. ${ }^{(10)}$ Primers and genomic DNA were lyophilized and sent as a powder in sealed $1.5-\mathrm{ml}$ microcentrifuge tubes to all participants. PCRs were performed in Ottawa in a manner similar to that of Williams et al. ${ }^{(2)}$ All reaction volumes were $25 \mu \mathrm{l}$, overlayered with $15 \mu \mathrm{l}$ of light mineral oil (Fisher). Each reaction consisted of $1 \times$ activity buffer $\left(1.5 \mathrm{~mm} \mathrm{MgCl}_{2}\right), 0.625$ units of Taq polymerase, $200 \mu \mathrm{M}$ total dNTPs (50 $\mu \mathrm{m}$ each), $200 \mathrm{~nm}$ primer, and $50 \mathrm{ng}$ of genomic DNA. The concentration of the primers was calculated based on the coefficient of extinction of each of the bases at $260 \mathrm{~nm}$. Only one primer and one genomic DNA sample were added to any single reaction. Fragment identities and sizes for all participants were calculated on the basis of the log of the molecular weight of the standards employed.

A total of 45 PCR cycles were performed in Ottawa, using a Coy thermocycler consisting of a $1-\min 94^{\circ} \mathrm{C}$ denaturation segment, a $1-\min 34^{\circ} \mathrm{C}$ annealing segment, and a 2 -min $72^{\circ} \mathrm{C}$ extension segment. Ramping was set at the fastest possible level between all segments. Following the final cycle, all strands were completed with a 10 -min $72^{\circ} \mathrm{C}$ segment followed by storage at $4^{\circ} \mathrm{C}$. Electrophoresis was performed in $1.3 \%$ agarose with Tris- $\mathrm{HCl}$ acetate/EDTA (TAE) buffer for $3 \mathrm{hr}$ at $70 \mathrm{~V}$, constant

TABLE 1 Primer Sequences

\begin{tabular}{lcl}
\hline $\begin{array}{l}\text { Primer } \\
\text { designation }\end{array}$ & $\begin{array}{l}\text { UBC } \\
\text { number }\end{array}$ & Sequence \\
\hline A & 209 & TGCACTGGAG \\
B & 225 & CGACTCACAG \\
C & 230 & CGTCGCCCAT \\
D & 234 & TCCACGGACG \\
E & 240 & ATGTTCCAGG \\
\hline
\end{tabular}

(UBC) University of British Columbia.

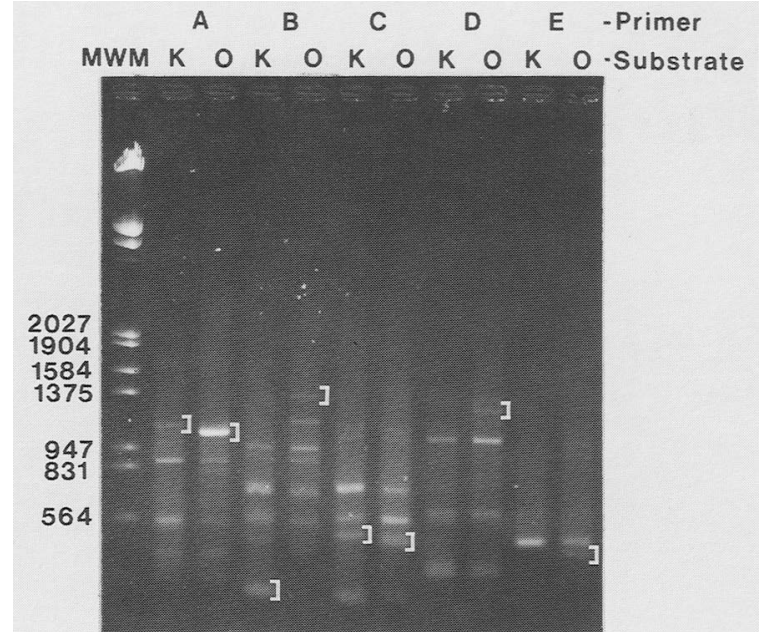

FICURE 1 DNA fragments amplified by five primers in Ottawa. (MWM) Molecular weight markers (sizes denoted at left in base pairs); $(A-E)$ primer designations (see Table 1$) ;(K, O)$ Kanota and Ogle genomic DNA; bracket (]) denote polymorphic fragment. voltage. Ethidium bromide-stained gels were visualized on a UV transilluminator.

Other participants used slightly different protocols as summarized in Table 2 . In addition, $\mathrm{AB}$ also used $1.8 \%$ agarose gels for separation of amplified fragments. AL used $1.9 \mathrm{mM} \mathrm{MgCl}_{2}$, with an annealing temperature of $35.5^{\circ} \mathrm{C}$ and separated fragments on $1.2 \%$ agarose gels. GS extended the denaturation period to $90 \mathrm{sec}$. In Ottawa, we set the annealing temperature in a Coy thermocycler to $32.5^{\circ} \mathrm{C}$ to achieve temperatures inside the tubes of $34^{\circ} \mathrm{C}$. GS placed the Coy thermocycler in a $4^{\circ} \mathrm{C}$ cold room for PCR runs and found that setting the annealing temperature at $34^{\circ} \mathrm{C}$ resulted in tube temperatures of $34^{\circ} \mathrm{C}$. $\mathrm{KK}$ also inserted an additional 1 -min $94^{\circ} \mathrm{C}$ denaturation segment at the start of the PCR run but reduced the cycling denaturation segment to $30 \mathrm{sec}$, increased the annealing temperature to $36^{\circ} \mathrm{C}$ for $45 \mathrm{sec}$, and decreased the extension segment to 1 min. WK increased reaction volumes to $50 \mu l$.

Actual temperature profiles in the Coy and Techne PHC-3 thermocyclers were determined using an external thermocouple inserted through the lid of a $600-\mu$ l reaction vial so that the thermocouple was immersed in the $25-\mu l$ reaction volume below the oil level. The thermocouple was calibrated and read with a Ranger Reader. Temperatures were recorded every $5 \mathrm{sec}$ throughout several cycles. Due to significant hole-tohole variation, measurements for representative holes in the center of the block only are reported.

\section{RESULTS AND DISCUSSION}

The fragments amplified and polymorphisms identified by the Ottawa laboratory for the five primers shared in this study are illustrated in Figure 1. The ma-
TABLE 2 Comparison of the Various Protocols and Thermocyclers Employed by Participants

\begin{tabular}{|c|c|c|c|c|}
\hline $\begin{array}{l}\text { Participant } \\
\text { designation }\end{array}$ & Thermocycler & $\begin{array}{l}\text { dNTP }(\mu \mathrm{M}) \\
\text { conc. }^{a}\end{array}$ & $\begin{array}{l}\text { Taq (units) } \\
\text { conc. }\end{array}$ & Percent gelatin \\
\hline GP & Coy & 200 & 0.625 & 0.000 \\
\hline $\mathrm{AB}$ & MJ Research & 100 & 0.625 & 0.001 \\
\hline WK & Techne PHC-3 & 200 & 2.5 & 0.000 \\
\hline LD & Perkin-Elmer 4800 & 200 & 0.625 & 0.000 \\
\hline $\mathrm{AL}$ & Techne PHC-3 & 100 & 1.0 & 0.001 \\
\hline GS & Coy & 100 & 1.0 & 0.000 \\
\hline KK & MJ Research & 100 & 2.5 & 0.000 \\
\hline
\end{tabular}

${ }^{a}$ Concentration for total dNTPs per reaction.

${ }^{\mathrm{b}}$ Amount of Taq polymerase per reaction. 


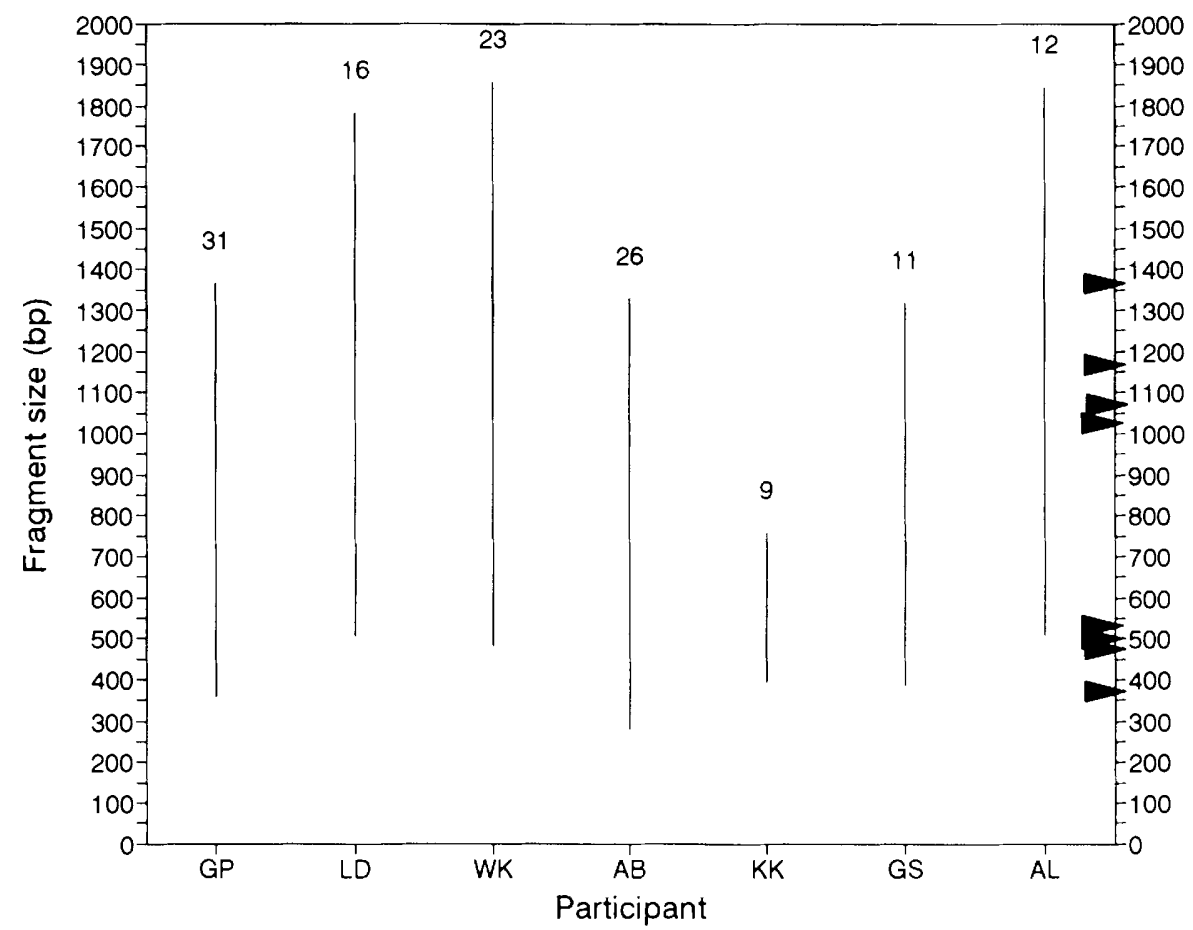

FIGURE 2 A comparison of the size range of DNA fragments amplified by the various participants. Vertical lines encompass size range of fragments amplified by designated participant. Numbers at top of size range lines correspond to the total number of fragments amplified by participant. The arrows on the right y-axis denote the sizes of the polymorphisms identified in Ottawa (Table 2). Participant initials are listed in the text. jority of the other participants $(\mathrm{AB}$ and KK were exceptions) generated either no amplified fragments or very few using the Ottawa protocol. However, using their own protocols, which were optimized for their own thermocycling machines, most participants were able to amplify several fragments with the test set of primers and genomic substrates (Fig. 2). Each laboratory amplified a different size range of fragments (Fig. 3). and, consequently, there was a decrease in the reproducibility of both the largest and smallest fragments amplified (Fig. 2) These size ranges can be roughly grouped into two classes, one including $\mathrm{LD}, \mathrm{WK}$, and $\mathrm{AL}$, all generated fragments $>1700$ bp but not $<480$ bp. The other four participants did not amplify fragments $>1400$ bp but were able to amplify fragments $<400 \mathrm{bp}$.

There are no obvious differences in protocols that could be correlated with these differences in the size range of fragments amplified. The size ranges obtained with the two Coy machines (Gp, GS) were very comparable as were results from the two Techne machines (WK, $\mathrm{AL})$. The size ranges obtained by the two $\mathrm{MJ}$ machines (AB, KK) were less comparable, but both favored small fragments. The type of thermocycler used was thus a key factor in determining the size range of fragments amplified.

The temperature profiles on two thermocyclers, the Coy and Techne PHC-3 were determined with an external thermocouple (Fig. 4). The temperature inside the tubes was significantly different from the temperature reported by the thermocycler at both temperature extremes, denaturation and annealing. The internal temperatures of tubes lagged behind the temperature reported by the Coy machine sufficiently to erase any semblance of a plateau at either the denaturation or the annealing temperature. However, we were able to generate amplified RAPD fragments more consistently on the Coy than on the Techne PHC-3. When the Techne PHC-3 was programed so that the actual tube temperatures would mimic the actual tube temperatures on the Coy, reproducibility was significantly greater (data not shown).

Table 3 summarizes the results from each laboratory compared with those from Ottawa for all of the participants. Considering only those laboratories that amplified fragments of the appropriate

FICURE 3 Reproducibility of amplified DNA fragments among laboratories. Asterisks denote polymorphic fragments (i.e., fragments that were only amplified in the presence of one of the genomic DNAs of one of the varieties tested). All other bands were amplified from genomic DNA of both varieties tested. The number of participants (including the Ottawa laboratory) who reproduced each fragment is denoted by the number immediately to the right of each band. 


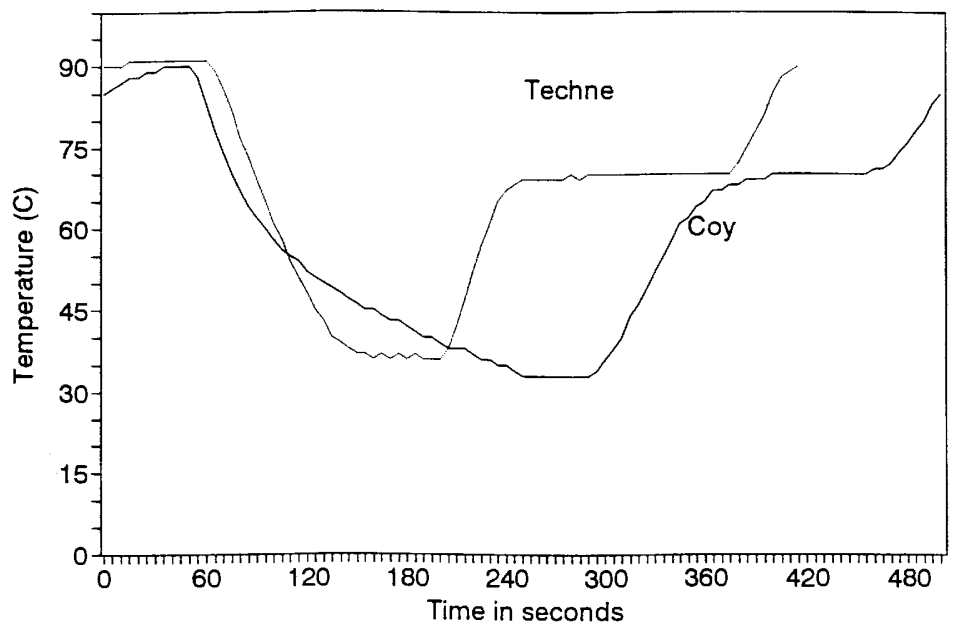

FICURE 4 A comparison of temperature profiles on two thermocyclers programed identically for RAPD analysis. Program was 1 min denaturation $\left(94^{\circ} \mathrm{C}\right), 1 \mathrm{~min}$ anealing $\left(34^{\circ} \mathrm{C}\right)$, and $2 \mathrm{~min}$ extension $\left(72^{\circ} \mathrm{C}\right)$. Ramping speed was set as fast as possible on both machines.

size range, the reproducibility averaged 97\% for four of the five primers (Fig. 2) The polymorphisms identified by primer $C$ in Ottawa were an exception in that they were poorly reproduced.

This study documents variability in RAPD fragments among laboratories. This variability is manifested in two ways: variability in the size range amplified, and intrinsic differences in the reproducibility of the primers involved. The type of thermocycler used appears to be the main source of the variation in size range. Grouping the participant results in terms of size classes also resulted in groupings in terms of thermocyclers used. Several researchers have observed that a change of as little as one degree at annealing temperature can lead to qualitatively different results in RAPD analysis. Given the competitive nature of RAPD amplification and the low stringency of homology required, perhaps it is not surprising that the type of thermocycler used should have such a dramatic effect. It is possible that higher anneal-

TABLE 3 Reproducibility of RAPD Polymorphisms Identified in Ottawa

\begin{tabular}{|c|c|c|c|}
\hline & \multicolumn{2}{|c|}{ Number of participants } & \multirow[b]{2}{*}{$\begin{array}{l}\text { Primer } \\
\text { reproducibility (\%) }\end{array}$} \\
\hline & $\begin{array}{l}\text { amplified fragments } \\
\text { in appropriate range }\end{array}$ & $\begin{array}{l}\text { amplified } \\
\text { polymorphism }\end{array}$ & \\
\hline \multirow{3}{*}{$\begin{array}{l}\text { Primer A } \\
\text { band B (1065 bp) } \\
\text { band C (1025 bp) }\end{array}$} & & & \\
\hline & 5 & 5 & \\
\hline & 6 & 6 & 100 \\
\hline \multicolumn{4}{|l|}{ Primer B } \\
\hline band B (1366 bp) & 5 & 4 & \\
\hline band I (371 bp) & 3 & 3 & 87.5 \\
\hline \multicolumn{4}{|l|}{ Primer C } \\
\hline band G (524 bp) & 7 & 1 & \\
\hline band H (504 bp) & 7 & 4 & 35.7 \\
\hline \multicolumn{4}{|l|}{ Primer D } \\
\hline band C (1172) & 6 & 6 & 100 \\
\hline \multicolumn{4}{|l|}{ Primer E } \\
\hline band B (467) & 4 & 4 & 100 \\
\hline Total & 43 & 33 & 76.7 \\
\hline
\end{tabular}

ing temperatures result in a decrease in the total number of fragments initially amplified and, hence, an increase in the competitiveness of larger fragments.

It is also evident from this comparison that certain primers give more reproducible results than others. The polymorphisms generated by primer $\mathrm{C}$ segregated in a Mendelian fashion over $80 \mathrm{~F}_{6}$ individuals in the Ottawa laboratory. However, these polymorphic fragments were almost entirely not reproduced by other laboratories. Primer $\mathrm{C}$ is not obviously unusual in sequence or base comparison. It has a GC content of $70 \%$, as does primer D, and $5^{\prime}$ end similar to primer B. The AT sequence at the $3^{\prime}$ end would lead to two weak hydrogen bonds at the most crucial sites for homology. ${ }^{(2)}$ The other four primers all have bases at the $3^{\prime}$ terminus, which form three hydrogen bonds when annealed.

One laboratory (that of $A B$ ) was able to reproduce almost all of the fragments amplified in Ottawa. AB was also able to reproduce the same amplification pattern when working with genomic DNA extracted from the same cultivars, according to their own protocols (data not shown). AB and GP both used thermocyclers that generated the same size class of amplified fragments, and almost identical protocols. All three of the laboratories that amplified many fragments using the standard protocol (including that of GP) used thermocyclers that generated amplified fragments of the second size class. The one other user of a thermocycler that amplified fragments in this second size class (GS) placed the thermocycler in a cold room, likely altering temperature profiles, especially at the annealing stage.

Devos and Gale, ${ }^{(9)}$ working with wheat, have also observed differences in amplification patterns, which were dependent on the type of thermocyler and primer used. They also noted that Taq polymerase concentrations of $2.5 \mathrm{U} / 50$ $\mu l$ reaction resulted in nonspecific DNA amplification patterns and found concentrations of $0.8 \mathrm{U} / 50-\mu \mathrm{l}$ reaction to be optimal. Differences in concentration of polymerase could explain some of the variation observed in this study.

This study demonstrates that RAPD polymorphisms can be successfully reproduced among laboratories. The majority of primers should generate reproducible polymorphisms when standard 
reaction conditions permit the amplification of appropriately sized fragments. This may be sufficient for some primers. Temperature profiles inside tubes must be similar if laboratories are to achieve comparable results. Although not technically difficult to perform, RAPD analysis is a complex process. Further studies are needed to clarify the variables involved and establish standard conditions so that RAPD results can be shared immediately among laboratories.

\section{ACKNOWLEDGMENTS}

This project was funded in part by Quaker Oats Canada, for which we are grateful. Additional support and resources provided by each of the participating institutes, especially by Agriculture Canada, Winnipeg Research Station, and Agriculture Canada, Plant Research Centre, are also gratefully acknowledged.

\section{REFERENCES}

1. Welsh, J. and M. McClelland. 1990. Fingerprinting genomes using PCR with arbitrary primers. Nucleic Acids Res. 18: 7213-7218.

2. Williams, J.G.K., A.R. Kubelik, K.J. Livak, J.A. Rafalski, and S.V. Tingey. 1990. DNA polymorphisms amplified by arbitrary primers are useful as genetic markers. $\mathrm{Nu}$ cleic Acids Res, 18: 6531-6535.

3. Martin, G.B., J.G.K. Williams, and S.D. Tanksley. 1991. Rapid identification of markers linked to a Pseudomonas resistance gene in tomato by using random primers and near-isogenic lines. Proc. Natl. Acad. Sci. 88: 2336-2340.

4. Penner, G., J. Chong, M. Levesque, S. Molnar, and G. Fedak. 1993. Identification of a RAPD marker linked to the oat stem rust gene Pg3. Theor. Appl. Genet. 85: 702-705.

5. Paran, I., R. Kesseli, and R. Michelmore. 1991. Identification of RFLP and RAPD markers linked to downy mildew resistance genes in lettuce using near-isogenic lines. Genome 34: 1021-1027.

6. Michelmore, R.W., I. Paran, and R.V. Kesseli. 1991. Identification of markers linked to disease resistance genes by bulked segregant analysis: A rapid method to detect markers in specific genomic regions using segregating populations. Proc. Natl. Acad. Sci. 88: 9828-9838.

7. Reiter, R.S., J.G.K. Williams, K.A. Feldmann, J.A. Rafalski, S.V. Tingey, and P.A. Scolnik. 1992. Global and local genome mapping in Arabidopsis thaliana by using recombinant inbred lines and random amplified polymorphic DNAs. Proc. Natl. Acad. Sci. 89: 1477-1481.

8. Kleinhofs, A. 1992. The North American barley genome mapping project progress report. Proceedings of the Second Public Workshop of the International Triticeae Mapping Initiative, 27-29 September, 1991, Manhattan, Kansas (ed. B.S. Gill, W.J. Raupp, and H. Corke), Report no. 10, September 1992. pp. 20-26. Genetic Resources Conservation Program, Division of Agriculture and Natural Resources, University of California, Davis.

9. Devos, K.M. and M.D. Gale. 1992. The use of random amplified polymorphic DNA markers in wheat. Theor. Appl. Genet. 84: $567-572$.

10. McCouch, S.R., G. Kochert, Z.H. Yu, Z.Y. Wang, G.S. Khush, W.R. Coffman, and S.D. Tanksley. 1988. Molecular mapping of rice chromosomes. Theor. Appl. Genet. 76: $815-829$.

Received December 7, 1992; accepted in revised form March 29, 1993. 


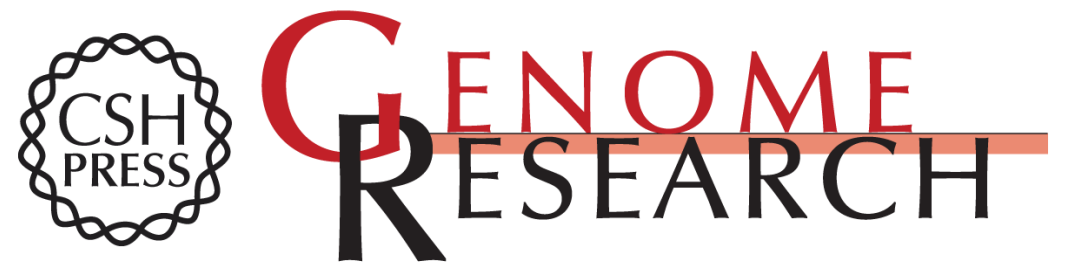

\section{Reproducibility of random amplified polymorphic DNA (RAPD) analysis among laboratories.}

G A Penner, A Bush, $\mathrm{R}$ Wise, et al.

Genome Res. 1993 2: 341-345

Access the most recent version at doi:10.1101/gr.2.4.341

References This article cites 9 articles, 3 of which can be accessed free at:

http://genome.cshlp.org/content/2/4/341.full.html\#ref-list-1

\section{License}

Email Alerting Receive free email alerts when new articles cite this article - sign up in the box at the Service top right corner of the article or click here.

\section{Affordable, Accurate Sequencing.}

To subscribe to Genome Research go to: https://genome.cshlp.org/subscriptions 